\title{
Comunicación de crisis y seguridad alimentaria. Caso listeriosis en la carne mechada
}

\author{
Crisis communication and food safety. Case of \\ listeriosis in larded meat
}

\author{
María-del-Mar Rodríguez-González; Iñigo Marauri-Castillo; Ignacio Armentia- \\ Vizuete; Flora Marín-Murillo
}

Cómo citar este artículo:

Rodríguez-González, María-del-Mar; Marauri-Castillo, Iñigo; Armentia-Vizuete, Ignacio; Marín-Murillo, Flora (2020). "Comunicación de crisis y seguridad alimentaria. Caso listeriosis en la carne mechada". Profesional de la información, v. 29, n. 6, e290605.

https://doi.org/10.3145/epi.2020.nov.05

Artículo recibido el 12-11-2019 Aceptación definitiva: 04-06-2020
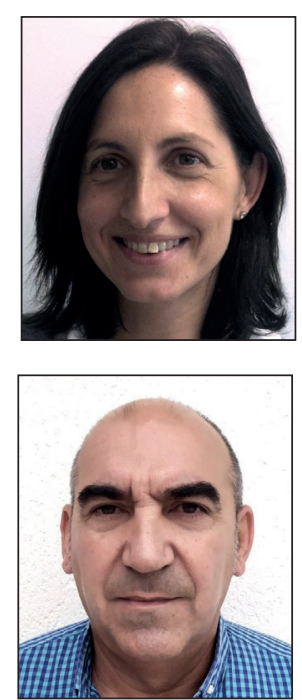

\begin{abstract}
María-del-Mar Rodríguez-González https://orcid.org/0000-0001-9121-1468

Universidad del País Vasco / Euskal Herriko Unibertsitatea (UPV/EHU)

Departamento de Periodismo II

Barrio Sarriena, $\mathrm{s} / \mathrm{n}$.

48940 Leioa (Bizkaia), España

mariadelmar.rodriguez@ehu.es $\bowtie$
\end{abstract}

Ignacio Armentia-Vizuete
https://orcid.org/0000-0002-6570-555X
Universidad del País Vasco / Euskal Herriko
Unibertsitatea (UPV/EHU)
Departamento de Periodismo
Barrio Sarriena, s/n.
48940 Leioa (Bizkaia), España
ignacio.armentia@ehu.es
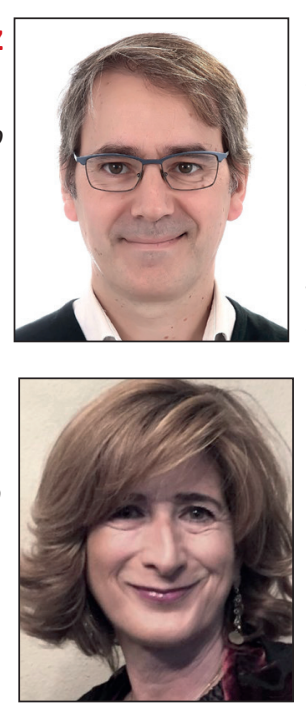

Iñigo Marauri-Castillo https://orcid.org/0000-0003-0883-8003

Universidad del País Vasco / Euskal Herriko Unibertsitatea (UPV/EHU)

Departamento de Periodismo II

Barrio Sarriena, $\mathrm{s} / \mathrm{n}$.

48940 Leioa (Bizkaia), España

inigo.marauri@ehu.es

\section{Flora Marín-Murillo https://orcid.org/0000-0003-2823-598X \\ Universidad del País Vasco / Euskal Herriko Unibertsitatea (UPV/EHU) \\ Dpto. de Com. Audiovisual y Publicidad \\ Barrio Sarriena, s/n. \\ 48940 Leioa (Bizkaia), España \\ flora.marin@ehu.eus}

\section{Resumen}

Esta investigación tiene como objeto el estudio de las principales políticas de comunicación llevadas a cabo por las instituciones públicas, de acuerdo con los sistemas nacionales y europeos de control en seguridad alimentaria, con el fin de gestionar las cada vez más numerosas y graves crisis alimentarias. Para ello, se ha seleccionado el brote de la listeriosis en la carne mechada La Mechá registrado el verano de 2019 en España como uno de los casos, junto con la crisis provocada por la bacteria E. coli en 2011, en los que las acciones comunicativas han generado una mayor controversia. Ante el compromiso de las autoridades nacionales y europeas de reforzar los sistemas de alertas y de control sanitario y alimentario, este artículo analiza la idoneidad en este caso de la gestión de la comunicación de esta crisis y estudia su importancia como herramienta principal para gestionar las crisis alimentarias, de manera que se puedan controlar los conflictos y reducir el alarmismo provocado por determinadas informaciones. Ante una crisis alimentaria, el único instrumento del que dispone el consumidor final para proteger su salud es la información. Si las autoridades competentes emiten mensajes discrepantes, ambiguos, especulativos o contradictorios, la sensación de descontrol y desinformación será mayor. La complejidad del ámbito en el que se desarrollan estas crisis, la seguridad alimentaria, exige que las autoridades públicas y los responsables de elaborar esas políticas de comunicación conozcan cómo funcionan los controles de seguridad nacionales y europeos, entre ellos el sistema de alerta rápida para alimentos y piensos (Rapid Alert System for Food and Feed, RASFF), que permite a los organismos nacionales y europeos responsables intercambiar información de manera rápida y eficaz, y la legislación pertinente. 


\title{
Palabras clave
}

Comunicación de crisis; Gestión de comunicación de crisis; Comunicación de salud; Políticas de comunicación; Seguridad alimentaria; Instituciones públicas; Listeria; Alimentos; RASFF; Diarios; Fuentes de información; Encuadres; Errores; Desinformación; Gestión.

\begin{abstract}
The purpose of this research is to study the main communication policies carried out by various public institutions, in accordance with national and European food safety control systems, in order to manage the growing number and severity of food crises. To this end, the outbreak of listeriosis in La Mechá tufted meat company registered in the summer of 2019 in Spain has been selected as one of the cases, together with the crisis caused by the bacteria E. coli in 2011, in which the communication policy of institutions has caused more controversy. Given the commitment of national and European authorities to strengthen the systems of alerts and health and food control, the study of this case aims to put on the table the suitability of the crisis communication management and to underline its importance as the main tool for managing food crises, so that conflicts can be controlled and alarmism caused by certain information can be reduced. In the face of a food crisis, the only instrument available to the final consumer to protect his health is information. If the competent authorities issue discrepant, ambiguous, speculative or contradictory messages, the feeling of lack of control and misinformation will increase. On the other hand, the complexity of the area in which these crises develop, food safety, requires that public authorities and those responsible for developing these communication policies know how national and European safety controls work, including the Rapid Alert System for Food and Feed (RASFF), which allows the responsible national and European bodies to exchange information quickly and efficiently, and the relevant legislation.
\end{abstract}

\section{Keywords}

Crisis communication; Crisis communication management; Health communication; Communication policies; Food safety; Public institutions; Listeriosis; RASFF; Newspapers; Information sources; Framing; Errors; Disinformation; Management.

\section{Financiación}

Este artículo es parte del proyecto "Seguridad alimentaria y cibermedios: temáticas, nuevas fuentes y servicios". Este proyecto, con referencia CSO2017-82853-R, ha obtenido financiación en la convocatoria 2017 de los proyectos de I+D+l del Programa estatal de investigación, desarrollo e innovación orientada a los retos de la sociedad promovido por el Ministerio de Economía, Industria y Competitividad. Sus autores forman parte del Grupo de Investigación Medialker (referencia GIU19/024).

\section{Introducción}

El 15 de agosto de 2019 los medios de comunicación españoles se hicieron eco del brote de intoxicación por listeria a partir de la alerta sanitaria acordada por la Junta de Andalucía, así como de la retirada del mercado de la carne mechada La Mechá como consecuencia del positivo de una de las muestras. Se trata de una bacteria común que puede entrar en la cadena alimentaria desde diversos focos: campos de cultivo, forraje del ganado o a través de varias especies de animales silvestres y domésticos. Un día después, el gobierno andaluz advirtió al resto de autonomías y a la Agencia Española de Seguridad Alimentaria (Aesan) de que podían haberse distribuido lotes del producto infectado en otras comunidades. El 21 de agosto, a medida que aumentaba el número de afectados, la Junta de Andalucía ordenó retirar del mercado el resto de productos comercializados por esta empresa. El 24 de septiembre la policía detuvo al dueño de la empresa y a su gerente como responsables de este brote que causó tres fallecidos, seis abortos y más de 200 afectados.

No se puede decir que España no tenga experiencia en la gestión de este tipo de crisis alimentarias. Desde que en 1981 falleciera la primera de las 700 víctimas por el consumo de aceite de colza desnaturalizado, se ha ido confeccionando un marco legal a nivel nacional y europeo. En el caso europeo, a partir del Tratado de Amsterdam y del de Lisboa nació primero el Libro verde (Comisión Europea, 1997) y después el Libro blanco sobre la seguridad alimentaria y sobre el principio de precaución (Comisión Europea, 2000). En ellos se hace hincapié en los protocolos o planes de contingencia, apartados en los que se aclara que los medios de comunicación son determinantes en la información que ofrecen y en cómo la ofrecen.

El despliegue normativo y de recursos no ha impedido, sin embargo, la aparición de crisis alimentarias en las últimas décadas. Entre las más relevantes con impacto directo en España se encuentran el ya mencionado envenenamiento por aceite de colza (1981), la crisis de las vacas locas (1996), la peste porcina (2001), la gripe aviar (2003 en Asia y 2017 en Cataluña), la leche en polvo contaminada para niños (2008), la contaminación por E. coli (2011) y la que nos ocupa en esta investigación: la listeriosis en la carne mechada (2019).

Las investigaciones sobre estas crisis también se han sucedido con diferentes enfoques. Se han centrado en

- la gestión comunicativa de la actividad mediática (Vázquez-Gestal; Fernández-Souto, 2014);

- la gestión de la comunicación de crisis en el sector de la alimentación y bebidas en España (Saura-Pérez, 2005); 
- la gestión de la información y la comunicación en emergencias, desastres y crisis sanitarias (Moreno-Millán, 2008);

- el papel que organizaciones tan importantes como la OMS juegan en estas crisis (Rocamora-Villena, 2012);

- la evolución de las crisis alimentarias/sanitarias de los últimos 30 años, así como los encuadres de la prensa española sobre una crisis sanitaria (López-Villafranca, 2012; 2013).

La transmisión de la información sobre la retirada de un alimento que provoca intoxicaciones, que contiene una bacteria mortal o que se propaga por un retraso en la información de la alerta entre las administraciones pertinentes, implica la colaboración de todas las instituciones afectadas de acuerdo a una política de comunicación bautizada como 360 grados (Véliz-Montero, 2006; CollRubio; Micó, 2019). Una comunicación integral en la que no se puede dejar a un lado la comunicación de riesgos, más allá de que ambos conceptos -riesgo y crisis-impliquen enfoques diferentes respecto a las relaciones de las organizaciones con su entorno. Mientras que la comunicación de crisis se ha enmarcado tradicionalmente en el ámbito corporativo y se ha desarrollado al amparo de la comunicación estratégica, la evolución de la comunicación de riesgos ha estado relacionada con los cambios que ha sufrido la conceptualización del riesgo (Rocamora-Villena, 2012).

En el momento de comunicar una crisis nos hallamos ante la situación unidireccional en la que un comunicador individual o colectivo envía un mensaje a otros o a la propia organización a la que pertenece. En este caso, el éxito se considera determinado por la capacidad de los expertos para ilustrar o persuadir al receptor que se supone pasivo y desinformado (Cámara-Hurtado, 2009). También puede generar un efecto negativo, la sobreinformación, que dificulta la distinción entre informaciones sólidas y otras menos contrastadas. Una precisa y rigurosa información por parte de las autoridades públicas en situaciones de crisis se cataloga como una eficiente y efectiva fuente de información para la ciudadanía (Van-der-Meer; Verhoeven, 2014), más aún en el contexto de una sociedad digital en la que se multiplican las visiones y las versiones. Las consecuencias de esta multiplicación de voces se agravan en el ámbito de la seguridad alimentaria (Gil-Calvo, 2009).

La magnitud de una crisis no puede explicarse sin la intervención de los medios de comunicación. Los medios, con su posibilidad de orientar la agenda pública, pueden crear falsos problemas sociales o magnificar problemas menores para convertirlos en prioritarios (Lukes, 2007). Esto puede desautorizar a las autoridades ante la opinión pública, de manera que la ciudadanía pierda su confianza en ellas. Más si se tiene en cuenta que en la actual sociedad del conocimiento los ciudadanos reciben mucha información, opinan y deciden a través de las redes sociales y llegan a influir en la estabilidad de los gobiernos e instituciones. De ahí la necesidad de conocer con exactitud las aportaciones de las nuevas tecnologías y de internet y de las redes sociales a la comunicación (Castillo-Esparcia; Almansa-Martínez, 2005; Segarra-Saavedra; Martínez-Sala; Monserrat-Gauchi, 2019). Todo ello hace que sea determinante crear protocolos de actuación marcados por la multilateralidad, de manera que se implique a todos los actores sociales, políticos, jurídicos y medios de comunicación.

Algunos autores matizan el enfoque defensivo que la comunicación de crisis tiene sobre su organización, y critican lo que consideran las verdaderas intenciones que hay detrás de las prácticas corporativas. Desde ese punto de vista, el modelo esconde un mecanismo de defensa empresarial que no siempre tiene por qué estar pensado para evitar el riesgo social (daños sobre la población), sino para minimizar los daños simbólicos sobre la organización. Además, este tipo de prácticas se han trasladado a las administraciones públicas, vaciando de contenido las prácticas de comunicación de riesgo y convirtiéndose en meras estrategias de relaciones públicas (Gonzalo-Iglesia; Farré-Coma, 2011).

La elección del estudio de la gestión de la comunicación de crisis de las instituciones por el caso de listeriosis en la carne mechada viene dada por el interés en identificar y categorizar las prácticas llevadas a cabo en la gestión de la comunicación de crisis, una parte cada vez más importante de la comunicación institucional (Saura-Pérez; García-García, 2010), de un caso de seguridad alimentaria. Esas prácticas se cuestionan a través de los medios de comunicación, que inician un juicio mediático en el que reparten inocencias y culpabilidades desde el primer día de la crisis.

\section{Protocolos en seguridad alimentaria}

El concepto de seguridad alimentaria no tiene un único significado. Por un lado, se refiere a la seguridad alimentaria en términos cuantitativos y puede corresponder a la noción política establecida en el orden internacional (food security). Por otro, puede hacer referencia a la misma en términos sanitarios (food safety), también denominada calidad sanitaria o seguridad sanitaria de los alimentos (King et al., 2017, p. 161).

Con el fin de garantizar la seguridad alimentaria, en los últimos años se ha confeccionado un marco legal a nivel comunitario. A partir del Tratado de Amsterdam y del de Lisboa nació el Libro verde (Comisión Europea, 1997) y después el Libro blanco sobre la seguridad alimentaria y sobre el principio de precaución (Comisión Europea, 2000).

El sistema de control alimentario europeo se rige por un sistema de alerta rápida compartida por los Estados miembros (Rapid Alert System for Food and Feed, RASFF) (Agencia Catalana de Seguridad Alimentaria, 2019) creado en 1979, de 
manera que cuando un miembro de la red dispone de información sobre la existencia de un riesgo grave para la salud humana derivado de un alimento o de un pienso, debe notificar inmediatamente esta información a la Comisión a través de dicho sistema.

Además del RASFF, los responsables de las agencias alimentarias nacionales de la UE elaboraron un informe en 2014 en el que se recogía que una de las prioridades era contar con protocolos de actuación que permitieran actuar y garantizar una buena gestión. Si bien los expertos aseguran que nadie puede asegurar el riesgo cero en alimentación, hay numerosos factores controlados a través de la normativa alimentaria. Por otra parte, el Reglamento (CE) 178/2002, de 28 de enero (Unión Europea, 2002) establece los principios y requisitos generales de la legislación alimentaria, creando la Autoridad Europea de Seguridad Alimentaria y fijando procedimientos para la seguridad alimentaria. Destaca asimismo el papel de la European Food Safety Autority (EFSA) y, en España, de la Agencia Española de Consumo, Seguridad Alimentaria y Nutrición (Aecosan), constituida mediante Real decreto 19/2014, de 17 de enero, que dispone de varios medios de comunicación.

La seguridad alimentaria actual se basa por tanto en un enfoque preventivo, de manera que no se espera a que se presente un problema para solucionarlo, se anticipa a su aparición. Para conseguirlo, el Reglamento 852/2004 (Unión Europea 2004 ) obliga a las empresas a implantar sistemas de autocontrol basados en los principios del análisis de peligros y puntos de control críticos (APPCC). Uno de los valores del APPCC es que puede adaptarse a cada alimento y al proceso tecnológico que se le aplica: se identifican los peligros concretos, se localizan las fases en las que pueden reducirse (como el horneado, que destruye los microorganismos en la carne mechada) y se monitoriza para descubrir y solventar cualquier problema antes de que el alimento salga de la fábrica.

La información sobre una alerta alimentaria puede llegar a las autoridades competentes a través de distintos medios: consumidores, medios de comunicación, controles oficiales, clientes o proveedores de la industria alimentaria. Si la industria tiene la certeza o, incluso, la sospecha de haber puesto en circulación un alimento que pueda suponer un riesgo para la salud de los consumidores, tiene la obligación legal de informar a las autoridades competentes y colaborar con ellas en todo momento. El problema, que puede desencadenar en una alerta, una retirada de producto o una intoxicación, nace cuando las autoridades tienen conocimiento de las crisis a través de terceros y reaccionan sin tener en cuenta una estrategia de comunicación global.

\section{Gestión de la comunicación de las crisis alimentarias}

La comunicación de crisis es una de las áreas de la comunicación institucional que más se ha desarrollado desde la década de los ochenta y su gestión se ha incluido dentro del área de comunicación de las empresas e instituciones (Schwarz, 2016; Xifra, 2009; Sotelo-Enríquez, 2001; González-Herrero, 1998; Piñuel-Raigada, 1997). La política de comunicación de crisis se ha incorporado a la filosofía comunicativa de muchas organizaciones, como una herramienta de comunicación institucional encargada de velar por la imagen de la organización y de restaurar y mantener la reputación (Sotelo-Enríquez, 2001). Schwarz explica que la comunicación estratégica de crisis se define como la gestión de la comunicación para detectar o prevenir crisis de manera proactiva, para prepararse ante posibles crisis, afrontar situaciones de crisis en curso y para gestionar las quejas post crisis y evaluar la comunicación organizacional en estas situaciones (Schwarz, 2016, p. 31). Esta generalización de la práctica de la comunicación se debe a varios factores, como la atención creciente que los medios de comunicación prestan a las catástrofes, así como al aumento de las demandas que las empresas afrontan por defectos y negligencias en los bienes y servicios que ofrecen en el mercado, más allá de que su culpabilidad esté o no probada (Rodríguez-Andrés; Sádaba-Garraza, 1999; González-Herrero, 1998; González-Herrero; Pratt, 1996).

Por otro lado, internet es el medio óptimo para llegar a la ciudadanía y a los públicos afectados al actualizar continuamente la información y aportar recursos multimedia que ayudan a entender una situación. Facilita por tanto la difusión del mensaje o la posición de la empresa ante el conflicto, pero también es el escenario en el que se desarrollan las crisis 2.0 (Castillo-Esparcia; García-Ponce, 2015). La velocidad, globalidad, emocionalidad, horizontalidad, omnipresencia y eternidad que caracteriza el mundo digital hace que este sea un entorno de riesgo para el nacimiento de nuevas crisis, al mismo tiempo que se define como el adecuado para tratar las turbulencias digitales antes de que comience la crisis (De-la-Cierva, 2015).

Más allá de que una organización sea la causante o no de la crisis, es la responsable de gestionarla de forma correcta. En esta labor, a la opinión pública le preocupa el comportamiento de los miembros de la organización. De hecho, las crisis surgen también por la falta de entendimiento entre la institución y la sociedad, que no comprende o está en desacuerdo con la conducta de la organización.
La seguridad alimentaria actual se basa en un enfoque preventivo: no se espera a que se presente un problema para solucionarlo, se anticipa a su aparición 
Este concepto de crisis, que entra en el ámbito de la comunicación procedente de la teoría de administración de empresas, reúne numerosas definiciones que coinciden en ser situaciones inesperadas, urgentes y graves, con amplia repercusión social y que comprometen la imagen de la institución (Losada-Díaz, 2010; Xifra, 2009; Saura-Pérez, 2005; Mitroff; Pearson, 2002; González-Herrero, 1998; Piñuel-Raigada, 1997). En el marco de la comunicación institucional, Lerbinger (2011) define el concepto de crisis como el de un acontecimiento en la vida de la organización que puede tener efectos negativos sobre el prestigio, la rentabilidad o la propia supervivencia del entorno social.

Con el fin de determinar cuáles puedan ser esos efectos negativos, es necesario conocer la naturaleza de la organización y sus escenarios de actuación, ya que si bien no hay dos crisis iguales, se puede hacer un mejor análisis de las posibles causas. La bibliografía sobre tipos de crisis se ha multiplicado en los últimos años (Schwarz, 2016; Coombs, 2015; Liu y Faustino, 2014), al mismo ritmo que lo hacían las propias crisis.

\section{Estrategias de comunicación ante un caso de crisis alimentaria}

Adelantarse a la información, transparencia en la difusión de la información, disponibilidad para atender a los medios y, sobre todo, la autoexigencia de decir siempre la verdad son las señas de identidad de una política de comunicación proactiva que se enmarca en un plan de prevención de crisis como parte de una estrategia de comunicación global (Xifra, 2009). El primer objetivo que persigue esta estrategia es recuperar el control de la situación, de ahí que esta opción se base en liderar la información que se ofrezca en ese momento sobre la crisis.

Por el contrario, una política de comunicación reactiva, que llega tarde en un clima degradado de opinión, con mensajes poco coherentes, e incluso contradictorios, puede resultar no efectiva porque el margen para ensayar sea insuficiente.

En esta línea, Fita (1999) recuerda algunas consideraciones a tener en cuenta en el diseño de la estrategia de comunicación:

- Estrategia del silencio: no hay reacción frente a las acusaciones que se nos imputan o se habla lo menos posible sobre los hechos que nos acontecen. Esta estrategia comporta un impacto negativo hacia nuestra imagen.

- Estrategia de la negación: la organización niega el incidente y rechaza cualquier interés o dedicación que se le interponga.

- Estrategia de la transferencia de responsabilidades: hace asumir la culpabilidad a un tercero para proteger a la organización.

- Estrategia de la confesión: reconocimiento de responsabilidades y colaboración con los medios de comunicación. Las explicaciones forman parte de esta estrategia.

\section{Comunicación de crisis y listeria}

Comunicación de crisis y listeria es un binomio que hasta ahora no ha tenido desarrollo académico en España. Sí lo ha tenido en otros países que han vivido crisis de seguridad alimentaria causadas por la bacteria Listeria monocytogenes. "La infección por listeria más grave de la historia" (Attaran et al., 2008, p. 739) se produjo en Canadá, país en el que una contaminación masiva de listeria en los productos de la compañía Maple Leaf Foods causó 20 muertos y miles de personas enfermas. Varios autores abordaron la gestión de la comunicación de crisis de la compañía afectada. Greenberg y Elliott (2009) destacan que, a diferencia de las actitudes adoptadas por otras compañías en situaciones similares, la empresa afectada asumió la completa responsabilidad de la situación y negó que lo ocurrido se debiera al fracaso de la regulación existente o de la gestión gubernamental (Greenberg; Elliott, 2009, pp. 189-190). Esa apuesta se saldó con un éxito comunicativo que permitió a la marca recuperar su imagen y la confianza del consumidor. Así lo constatan también otros autores que han estudiado el caso (Howell; Miller, 2010; Beauchamp; Littlefield, 2012).

Siete años después del caso registrado en Canadá, otro episodio de intoxicación por listeria afectó a la compañía estadounidense de helados y productos lácteos Blue Bell. Los productos contaminados con esta bacteria causaron tres muertos, así como una crisis de reputación para la compañía. Al igual que lo ocurrido en Canadá, Blue Bell supo reaccionar con acierto. Asumió la responsabilidad del problema, tomó por iniciativa propia la decisión de retirar el producto y gestionó con rapidez y honestidad el problema (Meisner; Hinderaker, 2020; Calley et al., 2019; Opat; Magness; Irlbeck, 2018; Ren, 2018).

\section{Objetivos e hipótesis}

En esta investigación se han fijado los siguientes objetivos:

- Estudiar cada una de las informaciones que sobre la listeriosis se han publicado en los principales medios de comunicación online españoles con el fin de conocer quién protagoniza esta crisis.

- Estudiar las diferentes declaraciones públicas y analizar las políticas de comunicación llevadas a cabo por las principales administraciones públicas: Junta de Andalucía, Ayuntamiento de Sevilla y Ministerio de Sanidad. 
El cumplimiento de estos objetivos pretende confirmar las siguientes hipótesis:

1. La gestión de la crisis de la listeriosis por parte de las instituciones públicas fue inadecuada.

2. En esta crisis se repiten los mismos errores que en otras similares.

3. La falta de coordinación y los enfrentamientos entre instituciones las convierten en protagonistas involuntarias del caso.

\section{Metodología}

La metodología que se ha seguido en la elaboración de esta investigación ha sido la del análisis de caso a partir de la realización del análisis de contenido, en el que la parte cualitativa ha tenido mayor peso que la cuantitativa. Se basa en las propuestas que sobre el análisis de contenido realizan autores como Krippendorff (1990) o Bardin (2002), quienes explican que la aproximación cuantitativa está fundada en la frecuencia de aparición de ciertos elementos del mensaje, mientras que la aproximación no cuantitativa recurre a indicadores no frecuenciales susceptibles de permitir inferencia.

Con este fin, se ha procedido a realizar una búsqueda exhaustiva de todas las informaciones sobre el brote de listeriosis publicadas en seis diarios digitales españoles: elpais.com, abc.es, lavanguardia. com, elmundo.es, eldiario.es y el confidencial.com. Según datos de ComScore (tabla 1), estos medios se encontraban entre los 10 ciberdiarios con mayor audiencia de España en agosto de 2019, mes en el que se inicia la crisis objeto de estudio. Cuatro de estas publicaciones son la versión online de periódicos con edición en papel -El país, El mundo, La vanguardia y $A B C$-, mientras que eldiario.es y elconfidencial.com sondiarios nativos digitales, es decir, productos creados específicamente para internet.

El período seleccionado comprende del 15 de agosto al 16 de octubre de 2019, fecha en la que se decreta el fin de la alerta sanitaria por el brote de listeriosis que tuvo lugar en la comunidad autónoma de Andalucía. Por medio de los buscadores de cada una de las cabeceras analizadas, se han recopilado 662 unidades noticiosas (tabla 2) en las que se incluyen noticias, entrevistas, reportajes, crónicas y artículos de opinión.
Tabla 1. Los 10 ciberdiarios españoles con mayor audiencia en agosto de 2019

\begin{tabular}{|l|c|}
\hline \multicolumn{1}{|c|}{ Diario } & $\begin{array}{c}\text { Usuarios únicos } \\
\text { (en miles) }\end{array}$ \\
\hline elmundo.es & 20.113 \\
\hline elpais.com & 19.163 \\
\hline lavanguardia.com & 17.779 \\
\hline abc.es & 17.248 \\
\hline 20minutos.com & 16.248 \\
\hline elespanol.com & 16.167 \\
\hline elconfidencial.com & 14.195 \\
\hline okdiario.com & 10.663 \\
\hline elperiodico.com & 9.114 \\
\hline eldiario.es & 7.882 \\
\hline
\end{tabular}

Fuente: ComScore

Tabla 2. Número de unidades noticiosas analizadas

\begin{tabular}{|l|c|}
\hline \multicolumn{1}{|c|}{ Diarios } & Unidades noticiosas \\
\hline elpais.com & 68 \\
\hline lavanguardia.com & 215 \\
\hline abc.es & 142 \\
\hline elmundo.es & 69 \\
\hline eldiario.es & 107 \\
\hline elconfidencial.com & 61 \\
\hline Total & 662 \\
\hline
\end{tabular}

Una vez obtenida la muestra, se ha estudiado cada una de las unidades noticiosas con el fin de determinar la presencia de las fuentes institucionales respecto al resto y de estudiar las declaraciones de los principales protagonistas de la crisis. Para ello se ha configurado la ficha de categorización cuyo esquema se muestra en el gráfico 1 . A través de ella se han estudiado las fuentes principales. Asimismo, se han analizado las declaraciones y se han clasificado en un encuadre temático con el fin de determinar qué visión ofrecen los medios de comunicación analizados acerca de la actuación de las instituciones públicas. Con ello, se ha pretendido dilucidar las estrategias comunicativas llevadas a cabo.

\subsection{Fuentes}

En el apartado de fuentes, se han contabilizado aquellas cuya información ha dado pie al encabezado de la noticia. Es decir, no están recogidas todas las posibles fuentes citadas en un texto, sino únicamente la que ha contribuido a facilitar el tema principal de dicha inserción. La fuente puede aparecer citada explícita o implícitamente en el título o en el subtítulo, aunque lo más habitual es que sea incluida en el primer párrafo. Por ello, el número total de fuentes atribuido a cada diario coincide con el de textos publicados.

Para la identificación de la "fuente de información", se ha considerado que sigue teniendo plena vigencia la ya clásica definición de De-Fontcuberta:

"Personas, instituciones y organismos de toda índole que facilitan la información que necesitan los medios para suministrar noticias" (De-Fontcuberta, 1993, p. 58).

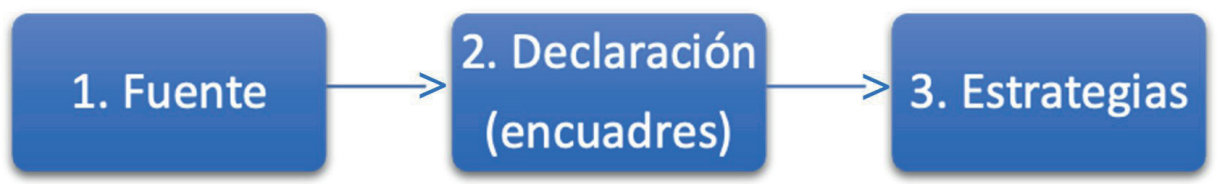

Gráfico 1. Ficha de categorización de las fuentes, declaraciones y estrategias 
Con el fin de contar con un número limitado de categorías, las fuentes encontradas se han clasificado en 11 grupos, a los que se ha añadido una más para aquellos casos en los que en el texto no se aluda al origen de la información. Son las siguientes:

1) Junta de Andalucía

2) Gobierno de España

3) Municipales-provinciales

4) Otros gobiernos

5) Médicos-científicos-expertos

6) Asociaciones de usuarios

7) Afectados por la infección

8) Empresas con listeria

9) Industria agroalimentaria

10) Judiciales

11) Otros

12) Sin fuentes.

\subsection{Declaraciones}

El apartado de declaraciones, cuyo análisis es fundamental para determinar la estrategia comunicativa diseñada por las instituciones públicas, se ha desarrollado a partir del estudio de la teoría del framing o del encuadre. La tarea de encuadrar fue descrita por Entman como:

"La selección de algunos aspectos de la realidad percibida y hacerlos más relevantes en un texto comunicativo, de manera que promuevan definiciones particulares de los problemas, interpretaciones causales, evaluaciones morales y/o recomendaciones para el tratamiento del asunto descrito" (Entman, 1993, p. 52).

A la hora de establecer los encuadres, se ha tenido en cuenta el listado de 11 mecanismos de encuadre que menciona Tankard (2001) para el reconocimiento y medida de nuevos enfoques: títulos, subtítulos, fotos, pies de foto, leads, selección de fuentes, selección de citas, logos, estadísticas y gráficos, y por último conclusiones y párrafos.

De este modo los encuadres más destacados, que no los únicos, en cada texto se han inducido del análisis de cada contenido (Vreese, 2005), y aunque algunos responden a la nomenclatura y definición de encuadres ya preestablecidos, otros se han determinado atendiendo a la especificidad del tema a tratar. El encuadre que hemos denominado de Servicio, por ejemplo, responde al concepto de Periodismo de servicio, definido por Diezhandino-Nieto (1993).

Así, a partir del estudio del encuadre, se han estudiado 97 declaraciones. Conviene aclarar que solamente se han contabilizado las declaraciones nuevas; las declaraciones oficiales y no oficiales con presencia en todos los diarios analizados se pueden repetir a lo largo del período estudiado en diferentes noticias en forma de despiece, destacado, cronología de los hechos, etc. Si por ejemplo, la ministra de Sanidad en funciones María Luisa Carcedo declara en una comparecencia pública que el origen del brote está en la fábrica de la carne mechada (22-08-2019), así aparece en todos los diarios ese mismo día y se repite durante los días siguientes. Sin embargo, en la muestra sólo se contabilizará una vez. Lo mismo sucede con otras fuentes. Así, cuando la asociación de consumidores Facua-Consumidores en Acción presenta por medio de un comunicado de prensa 15 medidas a partir de la crisis originada por la listeriosis con el fin de prevenir un nuevo caso de producto alimenticio contaminado, todos los medios de comunicación se hacen eco de ella. Sin embargo, nosotros contabilizamos una declaración una sola vez, la siguiente:

"Estas medidas deben acometerse de manera urgente, dadas las importantes carencias que tiene la legislación, que pueden desembocar en crisis de tanta gravedad como la de Magrudis, la cual podría haberse evitado si la normativa y los protocolos de control no tuviesen tantos agujeros" (16-09-2019).

Los encuadres destacados en los que se enmarcan las diferentes fuentes y declaraciones se muestran en el gráfico 2.

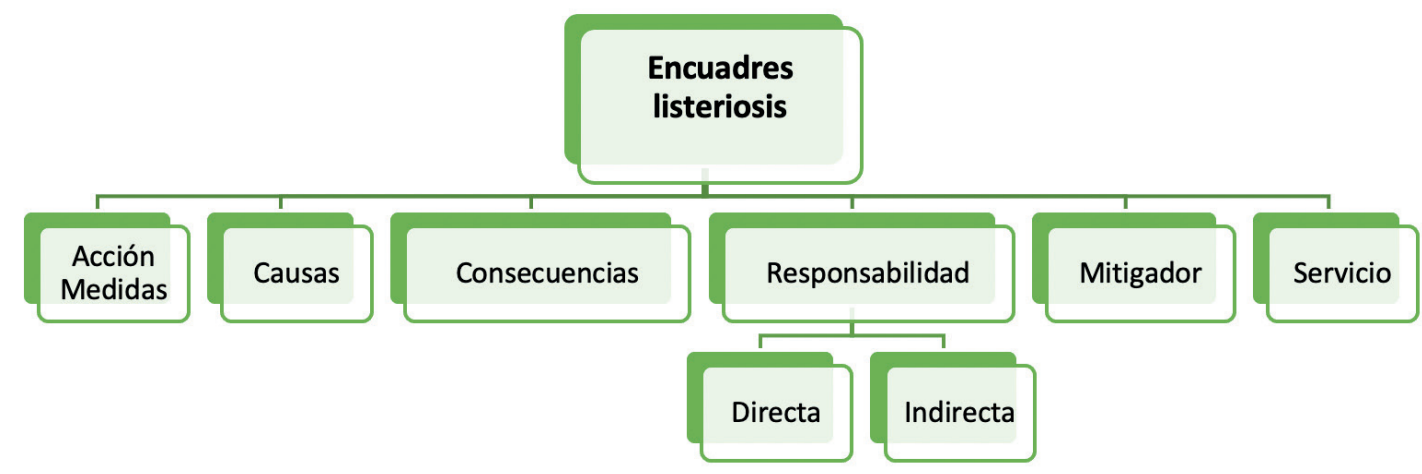

Gráfico 2 
De la relación e interpretación de las declaraciones, fuentes y acciones llevadas a cabo en estos encuadres, se determina la política de comunicación de las instituciones públicas, objeto central de nuestro estudio. Estos encuadres o marcos responden a los siguientes presupuestos y estrategias de comunicación recomendadas:

- Acción/medidas: ¿Qué hacen las instituciones, organismos y asociaciones respecto a la crisis? ¿Qué medidas se adoptan?

- Causas: ¿Cuál es la causa u origen de la infección por listeria? ¿A quién o quiénes se atribuye la responsabilidad y su reacción ante estas acusaciones?

- Consecuencias: ¿Qué consecuencias se derivaron de la infección, más allá de las sanitarias y económicas? El foco también se centra en las relacionadas con la credibilidad de un organismo, de las instituciones públicas y el tratamiento de su imagen.

- Responsabilidad directa / indirecta (Entman, 1993; Semetko; Valkenburg, 2000) ¿A quién se atribuye la responsabilidad directa de la listeriosis? ¿A quién se atribuye la responsabilidad en la gestión de la crisis? ¿Cómo se comunica?

- Mitigador: ¿Se destacan aquellos contenidos que atenúan o mitigan la gravedad de la crisis? ¿Qué organismos aluden directamente al final de la misma?

- Servicio: ¿Los contenidos ayudan a contextualizar el problema? ¿Se aporta información útil para el lector?

\subsection{Estrategia comunicativa}

La estrategia comunicativa a partir de las declaraciones y las fuentes estudiadas se determina de acuerdo a la clasificación en la que coinciden gran parte de los expertos en comunicación de crisis (tabla 3).

Tabla 3. Estrategias comunicativas recomendadas y no recomendadas ante una crisis

\begin{tabular}{|l|l|}
\hline \multicolumn{1}{|c|}{ Estrategia recomendada } & Estrategia no recomendada \\
\hline Gestionar de forma correcta el tiempo. Es clave para la resolución de la crisis & Cuanto más tiempo se tarde en reaccionar la respuesta es menos eficaz \\
\hline Transparencia en la información & Informaciones oficiales a cuentagotas \\
\hline Asumir la responsabilidad & Transferencia de responsabilidades a otros \\
\hline Pedir perdón & Señalar con nombre y apellidos otros culpables \\
\hline Confesión & Dejar que pase la "tormenta" sin asumir la culpa \\
\hline No mentir & Mentir consciente o inconscientemente \\
\hline Proactividad & Reactividad \\
\hline
\end{tabular}

Fuente: Elaborado con referencias de Quesada (2016); Schwarz (2016); Fink (2013); Xifra (2009); Bel-Mallén (2004); Fita (1999); Rodríguez-Andréz y Sádaba-Garraza (1999); González-Herrero (1998); Piñuel-Raigada (1997); Ogrizek y Guillery (1996); Westphalen y Piñuel-Raigada (1992).

En el apartado cualitativo, además de optar por la teoría del encuadre, este equipo de trabajo se puso en contacto con el departamento de prensa de la Junta de Andalucía, del Ayuntamiento de Sevilla y del Ministerio de Sanidad durante el mes de octubre de 2019 con el fin de realizar entrevistas a los representantes que jugaron un papel activo en esta crisis. La respuesta siempre fue la misma: "No es un buen momento, quizá más adelante".

\section{Resultados}

Se han estudiado 662 unidades noticiosas correspondientes a noticias, reportajes, entrevistas y artículos de opinión, así como la fuente principal de cada una de ellas. Asimismo, se ha estudiado el número de declaraciones obtenidas de las fuentes, que asciende a 97, y la estrategia comunicativa llevada a cabo en cada caso.

\subsection{Fuentes}

La Junta de Andalucía, y concretamente su Consejería de Salud y Familias, es la fuente más utilizada en las unidades noticiosas de los seis medios analizados (el 34,7\%). Tal y como se refleja en la tabla 4, 230 de las 662 tienen como fuente principal al Gobierno andaluz. La segunda fuente principal es la englobada bajo la denominación "Gobierno de España”, que incluye al Ministerio de Sanidad y Consumo y a sus agencias dependientes, como la Agencia Española de Seguridad Alimentaria y Nutrición (Aesan). Un total de 84 unidades noticiosas (el 12,6\%) están encabezadas por esta fuente. 68 (un $10,2 \%)$ corresponden a la variable "Otros gobiernos", que recoge citas de las comunidades de Madrid, Castilla y León y Valencia, en las que sus consejeros de Sanidad ofrecen información vinculada con la población afectada de esas comunidades. Las fuentes principales oficiales se completan con las municipales y provinciales, 32 (un 4,8\% del total), en su mayoría del Ayuntamiento de Sevilla, ciudad en la que está ubicada la empresa Magrudis, en la que se detectó el primer brote de listeria, aunque también de otros lugares, como la gaditana Paterna de Rivera, sede de la firma Sabores de Paterna, cuya carne mechada también sufrió la contaminación de la citada bacteria. En conjunto, 414 fuentes principales se encuadran en las fuentes oficiales, es decir, un $62,2 \%$ del total.

En el grupo de "Médicos, científicos y expertos en nutrición" se incluyen las aportaciones de especialistas en el ámbito sanitario y nutricional, pero que no hablan en representación de un organismo público. Son las fuentes principales de 42 unidades noticiosas (6,3\%).

Por lo que se refiere a las asociaciones de usuarios (un 4,6\% del total), la más citada como fuente principal es Facua-Consumidores en Acción y lo hace una vez en elpais.com, 15 en lavanguardia.com y ocho en abc.es, seguida de la Asociación El Defensor del Paciente -una vez en elpais.com y tres en lavanguardia.com-. 
Menor es la presencia, en términos generales, de los afectados por el brote de listeriosis (en 27 ocasiones, un $4 \%$ del total). abc.es y elmundo.es recurren a ellos en ocho ocasiones y cabe mencionar, a este respecto, la información publicada por elmundo.es:

"Que mi madre haya muerto por patologías previas no se lo cree nadie, ha muerto por la carne mechada" (2808-2019);

Y la de abc.es:

"Alerta sanitaria por listeriosis: 'Mi suegra de 86 años está en la UCI tras cenar un montadito de carne mechada'” (16-08-2019).

Las responsables de las tres empresas andaluzas en cuyos productos se detectó la bacteria de la listeria -Magrudis, Sabores de Paterna y La Montanera del Sur- apenas aparecen como fuente principal de las noticias (15 textos en total, un 2,2\%). Aun así, elpais.com, abc.es y elmundo.es recogieron testimonios del gerente de Magrudis y lavanguardia.com del abogado de la firma. Un número similar (13, un 1,9\%) se asocia a fuentes principales relacionadas con la industria agroalimentaria.

De media, en el 7,7\% de las unidades noticiosas no aparece ninguna referencia a la fuente principal de la noticia. El porcentaje más elevado corresponde a eldiario.es y el más bajo a elmundo.es.

Tabla 4. Desglose de distribución de fuentes principales en los diarios analizados

\begin{tabular}{|c|c|c|c|c|c|c|c|c|}
\hline \multirow{2}{*}{ Fuentes } & \multirow{2}{*}{ elpais.com } & \multirow{2}{*}{ lavanguardia.com } & \multirow{2}{*}{ abc.es } & \multirow{2}{*}{ elmundo.es } & \multirow{2}{*}{ elconfidecial.com } & \multirow{2}{*}{ eldiario.es } & \multicolumn{2}{|c|}{ Total } \\
\hline & & & & & & & $\mathbf{n}$ & $\%$ \\
\hline Junta de Andalucía & 32 & 93 & 34 & 21 & 20 & 30 & 230 & 34,7 \\
\hline Gobierno de España & 3 & 20 & 27 & 3 & 16 & 15 & 84 & 12,7 \\
\hline Municipales-provinciales & 3 & 13 & 3 & 4 & 2 & 7 & 32 & 4,8 \\
\hline Otros gobiernos & 1 & 21 & 25 & 6 & 1 & 14 & 68 & 10,3 \\
\hline Médicos/científicos/expertos & 6 & 6 & 8 & 5 & 9 & 8 & 42 & 6,3 \\
\hline Asociaciones de usuarios & 2 & 15 & 8 & 4 & 1 & 1 & 31 & 4,7 \\
\hline Afectados por la infección & 4 & 3 & 8 & 8 & 3 & 1 & 27 & 4,1 \\
\hline Empresas con listeria & 3 & 3 & 2 & 2 & 2 & 3 & 15 & 2,3 \\
\hline Industria agroalimentaria & 4 & 4 & 4 & 1 & 0 & 0 & 13 & 2,0 \\
\hline Judiciales & 4 & 10 & 2 & 6 & 1 & 7 & 30 & 4,5 \\
\hline Otros & 1 & 17 & 7 & 8 & 2 & 4 & 39 & 5,9 \\
\hline No aparece & 5 & 10 & 14 & 1 & 4 & 17 & 51 & 7,7 \\
\hline Total & 68 & 215 & 142 & 69 & 61 & 107 & 662 & 100 \\
\hline
\end{tabular}

\subsection{Encuadres}

El encuadre de "Consecuencias" fue el predominante en el 30,2\% de las unidades noticiosas publicadas (tabla 5). Las informaciones sobre los nuevos afectados, así como los fallecidos y abortos provocados por la infección, aglutinaron 200 contenidos. Este encuadre está relacionado directamente con las fuentes institucionales, responsables de comunicar el número de afectados por la listeria.

Por detrás, con un 16,7\% encontramos 111 informaciones que con un marco de "Acciones" se refieren a las actuaciones que organismos públicos como Ministerio de Sanidad, Junta de Andalucía, Organización Mundial de la Salud (OMS), y asociaciones de consumidores como Facua hicieron para controlar los efectos de la infección: emisión de alerta sanitaria, estudios de posibles afectados en distintas comunidades, retirada de productos, refuerzo del personal sanitario, etc. Con 104 textos, el 15,7\% del total, se sitúa el encuadre relacionado con la "Responsabilidad directa", aludiendo a las empresas Magrudis sobre todo, y Sabores de Paterna, como causantes de la infección.

El marco correspondiente al "Efecto mitigador" (12,2\%) y al de la "Responsabilidad indirecta" (11,9\%) aparecen a continuación. Así, en 79 textos el foco de la responsabilidad indirecta se centró en las acusaciones mutuas entre el Ministerio de Sanidad, la Junta de Andalucía y, en menor medida, el Ayuntamiento de Sevilla, así como en las declaraciones de Facua que giraban también en torno a las deficiencias en la gestión tanto antes como después de la crisis, apuntando directamente a la responsabilidad, en este caso indirecta, de unos u otros organismos públicos. En 81 textos el encuadre predominante es el "Mitigador". En ellos, se subrayan los aspectos positivos que aminoraban la gravedad de la crisis y sus consecuencias.

Las "Causas" del brote de listeriosis se destacan en el 6\%, correspondiente a 40 textos en los que se alude a las pésimas condiciones de las instalaciones, y a los análisis positivos por listeria, así como a los retrasos en la alerta sanitaria como agravantes de la crisis. Sólo en 48 informaciones, el 7,1\%, los medios optaron por un encuadre de "Servicio", aportando información útil para conocer mejor a qué se enfrentaban o recomendando y sugiriendo medidas para evitar la infección, por ejemplo. 
Tabla 5. Distribución de las unidades noticiosas según el encuadre

\begin{tabular}{|c|c|c|c|c|c|c|c|c|}
\hline \multirow{2}{*}{ Encuadres } & \multirow{2}{*}{ elpais.com } & \multirow{2}{*}{ lavanguardia.com } & \multirow{2}{*}{ abc.es } & \multirow{2}{*}{ elmundo.es } & \multirow{2}{*}{ elconfidecial.com } & \multirow{2}{*}{ eldiario.es } & \multicolumn{2}{|c|}{ TOTAL } \\
\hline & & & & & & & n & $\%$ \\
\hline Acciones/medidas & 8 & 45 & 15 & 5 & 15 & 23 & 111 & 16,8 \\
\hline Causas & 6 & 14 & 11 & 3 & 1 & 5 & 40 & 6,0 \\
\hline Consecuencias & 20 & 53 & 55 & 24 & 21 & 27 & 200 & 30,2 \\
\hline Mitigador & 7 & 42 & 22 & $x$ & 3 & 7 & 81 & 12,2 \\
\hline Responsabilidad directa & 15 & 30 & 18 & 16 & 6 & 19 & 104 & 15,7 \\
\hline Responsabilidad indirecta & 5 & 20 & 12 & 18 & 9 & 15 & 79 & 11,9 \\
\hline Servicio & 7 & 11 & 9 & 3 & 6 & 11 & 47 & 7,1 \\
\hline Total & 68 & 215 & 142 & 69 & 61 & 107 & 662 & 100 \\
\hline
\end{tabular}

\subsubsection{Declaraciones}

Se han estudiado 97 declaraciones atribuidas a las fuentes que se señalan en la tabla 6.

Tabla 6. Distribución de las declaraciones y su origen

\begin{tabular}{|c|c|c|}
\hline Fuente & N. de declaraciones & Acciones comunicativas \\
\hline Institucionales & 44 & Notas de prensa y comparecencias públicas \\
\hline Expertos & 16 & No se contemplan, cada medio busca al experto que cree conveniente \\
\hline Facua & 11 & Notas de prensa y ruedas de prensa \\
\hline Afectados & 10 & No se contemplan \\
\hline Judiciales & 7 & Notas de prensa a través de la Fiscalía de Sevilla \\
\hline $\begin{array}{l}\text { Empresas con listeria (Magrudis, Sabores } \\
\text { de Paterna y La Montanera del Sur) }\end{array}$ & 6 & $\begin{array}{l}\text { Nota de prensa } \\
\text { Declaraciones obtenidas de forma individual por personas cercanas a la } \\
\text { empresa } \\
\text { Agencia EFE }\end{array}$ \\
\hline Industria agroalimentaria & 3 & No se contemplan \\
\hline
\end{tabular}

Como se puede observar, la mayoría de las declaraciones (44) se obtienen de fuentes institucionales, entre las que se encuentran la Junta de Andalucía, el Gobierno a través del Ministerio de Sanidad, principalmente, fuentes municipales-provinciales - destacando las del Ayuntamiento de Sevilla- y las de otros gobiernos, sobre todo la Consejería de Sanidad de Castilla y León, la Comunidad Valenciana y la Comunidad de Madrid. Cada uno de estos organismos tiene a sus propios portavoces, a quienes se les atribuye la autoría de estas declaraciones. Así, en el caso de las declaraciones institucionales, el consejero de Salud y Familias de la Junta de Andalucía, Jesús Aguirre, protagoniza la mayoría de ellas, seguidas del presidente de la Junta de Andalucía, Juan Manuel Moreno, del consejero de Presidencia y portavoz del Gobierno, Elías Belmondo, y la ministra de Sanidad en funciones, María Luisa Carcedo.

Respecto a las acciones comunicativas de donde surgen estas declaraciones, destacan el recurso a la elaboración de notas de prensa y de ruedas de prensa. Mientras que el Ayuntamiento sevillano envía y publica en su web ocho notas de prensa, la Junta redacta tres, que también publica en su web corporativa, además de otra procedente de Canal Sur. Por último, el Ministerio de Sanidad, Consumo y Bienestar Social también publica cinco notas de prensa con un mensaje común: "Somos uno de los países más exigentes en seguridad alimentaria" y "La prioridad de las redes de alerta ha sido la adecuada asistencia a los afectados". Dos de ellas aparecen publicadas en el Centro de Coordinación de Alertas y Emergencias Sanitarias, perteneciente a este Ministerio. En la primera (23 de agosto de 2019) se da información general sobre el brote de listeriosis asociado al consumo de carne mechada y en la segunda (27-09-2019) se aporta un Informe de fin de seguimiento del brote de listeriosis.

Le siguen las declaraciones procedentes de diferentes expertos (16), principalmente los de seguridad alimentaria, como la vicepresidenta de la Sociedad Española de Seguridad Alimentaria (Sesal), Carmen Vidal. Respecto a las declaraciones protagonizadas por las asociaciones de consumidores y usuarios destaca Facua-Consumidores en acción, azote del consejero Aguirre desde que se iniciara la crisis al acusarlo de forma reiterada de su mala gestión. Esta organización de consumidores es también una de las protagonistas de esta crisis por constituir una plataforma de afectados, por ser la primera en exigir a la Junta de Andalucía que aclarara cuándo se hicieron las últimas inspecciones a la empresa Sabores de Paterna y después, al personarse como acusación particular de once afectados por el brote de listeriosis de Magrudis. Todo ello lo comunican a través de las correspondientes notas de prensa, aunque mediante su portavoz, Rubén Sánchez, también se obtienen declaraciones en dos ruedas de prensa. 
Respecto a los afectados, no se sigue un patrón común, aunque la tendencia es que no se incluyan declaraciones de los perjudicados por la bacteria con nombre y apellidos. Tan sólo se han recogido diez, y dos de ellas prefieren mantener su anonimato. Esta es una de las pocas unidades noticiosas en las que los afectados protagonizan el titular:

"El marido de una embarazada afectada por listeriosis: 'Pasamos la listeria con paracetamol'” (elmundo.es, 2208-2019).

Por otra parte, de la Fiscalía de Sevilla se han obtenido siete declaraciones protagonizadas en su mayoría por la jueza Pilar Ordóñez, de acuerdo a la apertura de un auto, que es público, o por declaraciones a un medio determinado:

"Fuentes de la Fiscalía sevillana han confirmado a El mundo de Andalucía la apertura de lo que técnicamente se conoce como diligencias de investigación" (24-08-2019).

Por último, de las empresas con listeria, Magrudis a través de su gerente José Antonio Marín es quien protagoniza cuatro de las seis declaraciones, la otra la realiza Hilario Aranda, representante legal de Marín y de su hijo como administrador único de la empresa. A José Antonio Marín se le atribuyen algunas de ellas centradas en afirmar a través de un comunicado de prensa que los propietarios

"no se explican lo sucedido, están en estado de shock y se están haciendo las investigaciones internas" (25-08-2019).

De su abogado es la siguiente:

"Ha habido otras responsabilidades paralelas de las que son responsables por culpa la invigilancia de las administraciones públicas" (26-09-2019).

Estas declaraciones se obtuvieron ante los periodistas que le esperaban en el edificio de los juzgados de instrucción de Sevilla después de que se hubiera decretado la entrada en prisión provisional de sus representados. La otra empresa, Sabores de Paterna, mediante su gerente Bartolomé Rodríguez, asegura: "La fábrica cumple a rajatabla las normas sanitarias" y lo hace en declaraciones a la Agencia EFE (06-09-2019).

El sector cárnico protagoniza las tres declaraciones que se atribuyen a la industria agroalimentaria; la Asociación Nacional de la Industria de la Carne de España (Anice) declara que el brote por listeriosis en la carne mechada vendida en Andalucía se trata de un caso "puntual" que requiere la "revisión del sistema" (abc.es, 12-09-2019); "Los fabricantes de carne mechada detectan ya alarma social entre los consumidores", así lo han indicado a Efeagro portavoces de las compañías Icarben, Embutidos Moreno Plaza y Embutidos Reina (23-08-2019).

\subsubsection{Estrategias de comunicación}

De todas las estrategias de comunicación señaladas en la metodología, se enumeran las más destacadas:

\subsubsection{Transferencia de responsabilidad}

En un primer momento ninguna institución pública asume su responsabilidad en la gestión de la crisis, y a medida que reciben acusaciones reaccionan señalando como culpable a otro organismo, ya sea en una rueda de prensa o durante una comparecencia en comisión parlamentaria extraordinaria para informar sobre el brote de listeria (31-08-2019). No toman la iniciativa por sí mismos ni se adelantan a esas posibles acusaciones, lo que indica la ausencia de un plan de comunicación de crisis institucional que marque la ruta ante los medios de comunicación y la ciudadanía. El hallazgo de productos con la marca La Mechá ocultados por Magrudis provoca continuos enfrentamientos entre la Junta de Andalucía, Ayuntamiento de Sevilla y el Ministerio de Sanidad. Así, el Gobierno andaluz culpa al Consistorio hispalense de que la empresa haya ocultado información. Al mismo tiempo cuestiona los medios de los que dispone para desarrollar sus competencias e insiste que revisará quitárselas.

El enfrentamiento genera confusión y desconfianza, como muestran títulos y subtítulos como este: "Un brote de listeria y de dudas", "La Consejería de Salud, contra las cuerdas por la cadena de fallos y las sombras en la gestión de la crisis de la listeriosis" (elmundo.es, 26-8-2019).

De las declaraciones realizadas ante los medios de comunicación por los representantes de la Junta de Andalucía y del Ministerio de Sanidad se refleja de nuevo una falta de criterio común para comunicar un mensaje. La ministra Carcedo asegura que se bloquea la producción y argumenta que algún procedimiento falló en la fabricación de la carne mechada La Mechá, por lo que se decide la paralización de toda la producción de la empresa fabricante. Por el contrario, la Junta de Andalucía desoye la advertencia y dice que sólo pueden contraer listeriosis quienes hayan consumido el producto contaminado.

"Todo el brote tiene que ver con el alimento contaminado y se debe olvidar la contaminación cruzada" (declaraciones publicadas en los diarios analizados el 20-08-2019). 
Quince días después de realizar la declaración que acabamos de señalar, la ministra de Sanidad en funciones censuraba al Gobierno andaluz por "la calidad y la oportunidad" de los datos que ofrecía. De hecho, afirmaba:

"No tenemos responsabilidad en la relación existente entre el Ayuntamiento y la Junta. En nuestras redes el interlocutor es la Junta" (elpais.com, 05-09-2019).

No obstante, ese mismo día reconoció la existencia de una "cadena de errores y responsabilidades acumuladas" en la crisis de la listeria.

Las acusaciones entre Junta de Andalucía y Ayuntamiento se extienden al ámbito político, sobre todo a partir de que el portavoz del Gobierno andaluz afirmara que la competencia en seguridad alimentaria la tenía el Ayuntamiento de Sevilla y que este se equivocara al comunicar que el brote se había producido en una fábrica de Málaga.

“Al día siguiente rectificó [era en una fábrica de Sevilla]. Ya el día 15 aplicamos la alerta” (elconfidencial.com, 2008-2019).

Todos los medios analizados reflejan el hecho de que el principal partido de la oposición, el PSOE, solicitara la comparecencia urgente en un pleno extraordinario del Parlamento andaluz del presidente de la Junta, Juan Manuel Moreno, para que detallara la "penosa y desastrosa" gestión de su Gobierno del brote de listeriosis en Andalucía.

También incluyen las críticas de otros partidos de la oposición, como Adelante Andalucía. Una de sus portavoces, Inmaculada Nieto, afirma que la "única salida" del consejero de Salud y Familias, Jesús Aguirre, tras su "nefasta gestión" en la crisis de la listeriosis es "dimitir y reconocer que le viene muy grande"; "No nos pueden engañar y confundir", insiste el representante del PSOE.

"Ni siquiera hay un teléfono de información para que puedan llamar los posibles afectados por la listeria. El consejero habló de marca blanca y ahora parece que no existe y están confundiendo a todos. Queremos datos" (elconfidencial.com, 23-08-2019).

\subsubsection{Estrategia de la negación}

El abanderado de esta estrategia, propia de una política de comunicación reactiva, es el consejero andaluz de Salud y Familias, Jesús Aguirre, que entre la campechanía y el recurso a afirmaciones controvertidas se convierte en protagonista de esta crisis; atrae las críticas mientras eclipsa las causas y la respuesta a la crisis. Aguirre asegura que la gestión de la Junta sobre la crisis alimentaria provocada por el brote de listeriosis ha sido "transparente" e "impecable" y que siempre ha actuado con "la mayor brevedad posible" para atajarla.

"No sé nada de la empresa afectada, ni la he visto, ni sé dónde está ni he ido en mi vida. Esas son competencias del Ayuntamiento de Sevilla".

Esta es una de las citas recogidas en el estudio y publicadas en forma de entrevista cuyo titular es toda una declaración de intenciones:

"Me asusté cuando se triplicaron los casos de listeriosis. Se me cayeron dos lagrimones" (elconfidencial.com, 28-08-2019).

Si bien tiene claro que el mensaje se centra en culpar al Ayuntamiento de Sevilla, en muchas ocasiones lo lleva al terreno personal, y esta entrevista es uno de los mejores ejemplos.

"iYo no he mentido en mi puñetera vida! Y si algo he pedido yo a mi gente es transparencia y claridad. (...) Yo leo información para dar sólo el visto bueno. Hemos ido cambiando en función de lo que nos decían" (elconfidencial. com, 28-08-2019).

Los técnicos no se defienden de esta acusación velada, pero el Ayuntamiento sí y lo hace siguiendo la pauta que las instituciones públicas han marcado: señalar a otro como responsable. El Consistorio sevillano también es uno de los objetivos de las acusaciones procedentes del responsable de Magrudis; Marín Ponce reparte culpas a partes iguales con la Junta de Andalucía y con el Ayuntamiento de Sevilla. A la primera por no haber realizado inspección alguna y al segundo, por no detectar anomalías en las revisiones realizadas en 2016 y 2017.

Los seis diarios analizados publican los argumentos que constituyen la defensa del Ayuntamiento que, mediante un comunicado, informa que las inspecciones de Consumo a Magrudis se realizaron

"de acuerdo con las directrices europeas, la clasificación que se establece en las empresas, el funcionamiento de los sistemas de autocontrol y los programas de prioridades y los planes especiales que define la Junta de Andalucía en el marco de sus competencias" (eldiario.es, 06-09-2019).

\subsubsection{Estrategia del silencio}

En la última semana de julio ya se tenía constancia de un aumento anormal de los casos de listeriosis y el 9 de agosto se conocía la existencia de una partida de carne mechada contaminada. Sin embargo, las administraciones públicas implicadas se mantuvieron en silencio y no
El estudio ha permitido confirmar que la gestión de la crisis por parte de las instituciones públicas fue inadecuada 
decretaron la alerta sanitaria hasta el 15, de manera que durante ese tiempo los productos contaminados siguieron comercializándose, lo que agravó la extensión del brote. A pesar de que desde el 13 de agosto se sabía que la carne contaminada pertenecía a la empresa $\mathrm{Ma}$ grudis, los servicios sanitarios de la Junta tardaron otros ocho días en decretar la alerta para el resto de productos de la firma, incluida una partida comercializada como marca blanca.

\section{Conclusiones}

El estudio de las 662 unidades noticiosas recogidas en seis de los principales diarios online en España acerca de la infección por listeriosis producida en agosto y septiembre de 2019 ha permitido confirmar que, tal y como se indicaba en la hipótesis 1 de esta investigación, la gestión de la crisis por parte de las instituciones públicas fue inadecuada. A diferencia de las recomendaciones fijadas en la bibliografía académica de este campo (Quesada, 2016; Fink, 2013; Xifra, 2009; Bel-Mallén, 2004), la política de comunicación que siguen las tres administraciones públicas implicadas (nacional, autonómica y local) se caracteriza por una patente falta de coordinación y por la emisión de mensajes centrados en la evasión de responsabilidades.

La falta de asunción de responsabilidades se refleja en la precrisis, en la crisis y en la postcrisis (García-Ponce; Smolak-Lozano, 2013) de este caso.

En la precrisis por los errores en la gestión y el control de irregularidades, como:

- la razón por la que la empresa comercializadora de la carne contaminada no estaba a nombre del dueño real;

- por no impedir que operara en el mercado sin el certificado de Sanidad durante dos años;

- por permitir su actividad sin obtener el certificado agroalimentario;

- por permitir que la empresa responsable estuviera cinco años sin darse de alta en el registro de actividades del Ayuntamiento.

En la crisis, la falta de asunción de responsabilidades se plasma en el cruce de acusaciones entre las administraciones implicadas. Su deficiente gestión las convierte en protagonistas involuntarias de una crisis de la que deberían ser solución y acaban siendo parte del problema. Como ya sucediera con la crisis del pepino (Vázquez-Gestal; Fernández-Souto, 2014) y con la del huevo contaminado por fipromil (Rodríguez-González el al., 2017), la crisis alimentaria se transforma en una crisis institucional y una crisis política enmarcada en este caso en la comunidad andaluza. Confirmamos así lo establecido en la hipótesis 2 con la que partía esta investigación.

El “pimpampún” político, como titulaban algunos medios (eldiario.es, 21-08-2019) sólo logra confusión. Conviene recordar en este apartado que

"quien ostenta un cargo de autoridad (Consejería, Ministerio o incluso Presidente del Gobierno, según la gravedad del caso), si no sabe dar respuestas expertas lo que genera es desconfianza y alarma" (Revuelta el al., 2014).

El protagonismo no buscado tiene un reflejo claro en la cobertura informativa de la crisis. La proporción de fuentes institucionales como fuentes principales de las unidades noticiosas así lo atestigua. Si tomamos en consideración las procedentes de la Junta de Andalucía y de sus diferentes organismos, las del Gobierno de España y otros gobiernos autonómicos y las municipales y provinciales, el porcentaje global se sitúa en el 62,3\%. Un estudio de Mayoral-Sánchez (2005) sobre el uso de fuentes en El país, El mundo, ABC, La vanguardia y La razón ya recogía la presencia de un 37,1\% de fuentes oficiales, aunque advertía que este porcentaje podía ser superior, ya que la mayor parte de las informaciones procedentes de agencia también remitían a fuentes oficiales.

Esta presencia de fuentes en el caso de la listeriosis muestra algunas divergencias con las detectada por López-Villafranca (2012, pp. 235-236) en su estudio sobre los encuadres sanitarios en ABC, El mundo y El país, en los casos de la gripe $A$ y de la bacteria E. coli, esta última conocida como la "crisis de los pepinos". En esta segunda crisis las fuentes más citadas fueron las correspondientes a las entidades afectadas (empresarios agrícolas, asociaciones agrarias, etc.). En cambio, durante la alerta por listeriosis la presencia tanto de las empresas afectadas por el brote, como del sector agro-alimentario, es residual y el conjunto de los seis medios se refleja, respectivamente, en el $2,2 \%$ y $1,9 \%$ respectivamente. Estos datos confirman así el enunciado de la hipótesis 3 del estudio.

No son sin embargo los únicos. El protagonismo en las fuentes principales tiene su correspondencia en las declaraciones principales recogidas en las unidades estudiadas. Cerca de la mitad de las 97 declaraciones recogidas, 44 , pertenecen a fuentes institucionales. Por el contrario, sólo seis de las 97 , poco más de un $6 \%$, corresponden a las empresas responsables de la infección.

Esta impresión se refuerza si se toman como referencia los encuadres dominantes en las unidades noticiosas analizadas. Tal y como se ha podido comprobar en la investigación, también en los encuadres se refuerza el protagonismo no deseado de las instituciones públicas en esta crisis. Una de cada tres de las 662 unidades estudiadas está marcada por el 
encuadre de las "Consecuencias", en las que el protagonismo corresponde a las instituciones. A ello hay que sumar que el $12 \%$ está encuadrado en el marco de la "Responsabilidad indirecta", en el que las referencias a la gestión deficiente y al cruce de acusaciones son una constante. Resulta revelador que ese encuadre esté ligeramente por debajo del de "Responsabilidad directa", que es el que atañe a las empresas en las que se produjo la infección por listeria.

Entre las estrategias de comunicación de las instituciones públicas que han sido detectadas en la investigación, se ha constatado la aplicación de decisiones comunicativas alejadas de las recomendaciones de los expertos. Así, la Junta de Andalucía, el Ayuntamiento de Sevilla y el Ministerio de Sanidad se enzarzan en una estrategia de transferencia de responsabilidades que causa confusión y desconfianza, como muestran títulos y subtítulos como este:

"Un brote de listeria y de dudas" "La Consejería de Salud, contra las cuerdas por la cadena de fallos y las sombras en la gestión de la crisis de la listeriosis" (elmundo.es, 26-8-2019).

Asociada con la anterior, destaca la estrategia de la negación, propia de una política de comunicación reactiva que conviene evitar (Xifra, 2009). El referente en este sentido es el consejero andaluz de Salud y Familias, Jesús Aguirre. Con sus declaraciones, atrae las críticas mientras eclipsa las causas y la respuesta a la crisis.

A la transferencia de responsabilidades y la negación se suma la estrategia del silencio. En la última semana de julio ya se tenía constancia de un aumento anormal de los casos de listeriosis y el 9 de agosto se conocía la existencia de una partida de carne mechada contaminada.

Sin embargo, las administraciones públicas implicadas se mantuvieron en silencio y no decretaron la alerta sanitaria hasta el 15, de manera que durante ese tiempo los productos contaminados siguieron comercializándose, lo que agravó la extensión del brote. A pesar de que desde el 13 de agosto se sabía que la carne contaminada pertenecía a la empresa Magrudis, los servicios sanitarios de la Junta tardaron otros ocho días en decretar la alerta para el resto de productos de la firma, incluida una partida comercializada como marca blanca.

La falta de asunción de responsabilidades también se muestra en la postcrisis. Este equipo de trabajo se puso en contacto con el Departamento de Prensa de la Junta de Andalucía, del Ayuntamiento de Sevilla y del Ministerio de Sanidad durante el mes de octubre de 2019 con el fin de realizar entrevistas a los representantes que jugaron un papel activo en esta crisis. La respuesta siempre fue similar: “No es un buen momento, quizá más adelante”. Esta respuesta por sí misma transmite falta de transparencia y opacidad sobre las actuaciones públicas llevadas a cabo.

Se da la paradoja de que, desde un punto de vista técnico, la gestión pública de las alertas basada en un sistema coordinado a través de Aesan y de la UE funciona correctamente. Sin embargo, en la transmisión de la información a un nivel más local se detectan errores que además se ocultaron:

- la Junta de Andalucía tenía constancia del incremento de los casos de listeriosis desde el 15 de julio, los protocolos para la detección del origen no se pusieron en marcha hasta el 5 de agosto;

- la Consejería de Salud y Familias de la Junta de Andalucía sabía desde el 31 de julio que la empresa fabricante de la carne contaminada, Magrudis, había hecho obras pero nunca informó al Ayuntamiento de Sevilla, que tiene transferidas las competencias;

- uno de los clientes de la empresa Magrudis puso en el mercado carne mechada afectada sin marca y con errores de etiquetado.

Estas son algunas muestras que revelan una falta de coordinación, e incluso de información sobre el organismo al que se deben comunicar las irregularidades que se detecten a lo largo de todo el proceso de comercialización de un producto alimentario.

El desarrollo de los hechos sirve además para comprobar que los efectos negativos en la gestión y la imagen de las instituciones públicas se podría haber evitado con previsión y coordinación. Tres semanas después del comienzo de la crisis, la Junta de Andalucía y Ayuntamiento de Sevilla sí llegaron a una estrategia común: dejar de culparse entre ellos y centrar la responsabilidad única en Magrudis. Así lo reflejan titulares como este:

“El Gobierno andaluz y el Consistorio de Sevilla sellan la paz y culpan a Magrudis como 'única responsable' de la crisis de listeriosis" (eldiario.es, 05-09-2019).

No sólo eso, este mismo día comunican de forma conjunta que las dos administraciones acuerdan reforzar la coordinación para hacer frente a la crisis alimentaria que había dejado ya más de 200 afectados, tres fallecidos y cinco abortos.

Por lo tanto, y en síntesis, consideramos cumplidos los objetivos marcados en la investigación y confirmadas las hipótesis de las que se partía. Tal y como sugiere la bibliografía académica, la gestión de la comunicación de crisis precisa coordinación, un mensaje único, una actitud proactiva y rapidez y precisión en la respuesta. Ninguna de estas condiciones se dio en la comunicación acerca de la infección de listeriosis detectada en Andalucía en agosto de 2019. Los resultados de esta investigación complementan la visión que sobre comunicación de crisis y listeria se ha analizado ya en países como Estados Unidos (Meisner; Hinderaker, 2020; Calley et al., 2019; Opat; Magness; Irlbeck, 2018; Ren, 2018) y Canadá (Greenberg; Elliott, 2009; Howell; Miller, 2010; Beauchamp; Littlefield, 2012). A diferencia de estas investigaciones, y 
he aquí una de las aportaciones de este trabajo, el análisis se centra no en la comunicación de la empresa, sino en la labor comunicativa de las instituciones. Supone una nueva aportación a un campo, el de la comunicación de crisis de las instituciones, cuya vigencia y estudio son más relevantes que nunca.
La gestión de la comunicación de crisis precisa coordinación, un mensaje único, actitud proactiva, rapidez y precisión en la respuesta; ninguna de estas condiciones se dio en este caso

\section{Referencias}

Agencia Catalana de Seguridad Alimentaria (2019). EI RASFF: Sistema de alerta rápida para alimentos y piensos. Agencia Catalana de Seguridad Alimentaria. Generalitat de Catalunya.

http://acsa.gencat.cat/es/detall/article/El-RASFF-Sistema-dalerta-rapida-per-a-aliments-i-pinsos

Attaran, Amir; MacDonald, Noni; Stanbrook, Matthew B.; Sibbald, Barbara; Flegel, Ken; Kale, Rajendra; Hébert, Paul C. (2008). "Listeriosis is the least of it". Canadian Medical Association journal, v. 179, n. 8, pp. 739-740. https://doi.org/10.1503/cmaj.081477

Bardin, Laurence (2002). Análisis de contenido. Madrid: Akal. ISBN: 8476000936

Beauchamp, Kimberly A.; Littlefield, Robert S. (2012). "The maple leaf foods recall: best practice interaction during a food-related crisis". International journal of business continuity and risk management, v. 3, n. 1, pp. 1-18. https://doi.org/10.1504/IJBCRM.2012.045524

Bell-Mallén, José-Ignacio (2004). Comunicar para crear valor: la dirección de comunicación en las organizaciones. Pamplona: Universidad de Navarra, Eunsa. ISBN: 8431321660

Calley, Brandyl-Brooks; Meyers, Courtney; Gibson, Courtney; Irlbeck, Erica (2019). "A comparative content analysis of news stories and press releases during the 2015 blue bell ice cream recall". Journal of applied communications, v. 103, n. 3. https://doi.org/10.4148/1051-0834.2213

Cámara-Hurtado, Montaña (2009). “La comunicación del riesgo en las crisis alimentarias”. En: Moreno-Castro, Carolina (ed.). Comunicar los riesgos. Ciencia y tecnología en la sociedad de la información. Madrid: Biblioteca Nueva, pp. 85-114. ISBN: 9788497429269

http://scienceflows.com/wp-contenido/uploads/2015/12/Comunicar-los-riesgos-6-La-comunicacion-del-riesgo-en-lascrisis-alimentarias.pdf

Castillo-Esparcia, Antonio; Almansa-Martínez, Ana (2005). “Relaciones públicas y tecnología de la comunicación. Análisis de los sitios de prensa virtuales". Organicom, año 2, n. 3, pp. 135-149.

http://www.eca.usp.br/departam/crp/cursos/posgrad/gestcorp/organicom/re_vista3/132.pdf

Castillo-Esparcia, Antonio; García-Ponce, Damián (2015). Comunicación de crisis 2.0. Madrid: Fragua. ISBN: 97884 70746666

Coll-Rubio, Patricia; Micó, Josep-Lluís (2019). “La planificación estratégica de la comunicación en la era digital. Los casos de estudio de Wallapop, Westwing y Fotocasa". Vivat academia, n. 147, pp. 125-138.

https://doi.org/10.15178/va.2019.147.125-138

Comisión Europea (1997). Principios generales de la legislación alimentaria de la Unión Europea. Libro verde de la Comisión. https://eur-lex.europa.eu/LexUriServ/LexUriServ.do?uri=COM:1997:0176:FIN:ES:PDF

Comisión Europea (2000). Libro blanco sobre seguridad alimentaria.

https://eur-lex.europa.eu/legal-content/ES/ALL/?uri=celex:51999DC0719

Coombs, W. Timothy (2015). "The value of communication during a crisis: Insights from strategic communication research". Business horizons, v. 58, n. 2, pp. 141-148.

https://doi.org/10.1016/j.bushor.2014.10.003

De-Fontcuberta, Mar (1993). La noticia. Pistas para percibir el mundo. Barcelona: Paidós. ISBN: 8475099505

De-la-Cierva, Yago (2015). Comunicar en aguas turbulentas. Un enfoque ético para la comunicación de crisis. Pamplona: Eunsa. ISBN: 9788431330323

Diezhandino-Nieto, Pilar (1993). “El periodismo de servicio, la utilidad en el discurso periodístico”. Análisi, n. 15, pp. 117-125.

https://www.raco.cat/index.php/Analisi/article/view/41192

Entman, Robert M. (1993). “Framing: Toward clarification of a fractured paradigm”. Journal of communication, v. 43, n. 4, pp. 51-58.

https://doi.org/10.1111/j.1460-2466.1993.tb01304.x 
Fink, Steven (2013). Crisis communications: The definitive guide to managing the message. New York: McGraw Hill. ISBN: 9780071799218

Fita, Jaume (1999). Comunicación en programas de crisis. Barcelona: Ediciones Gestión 2000. ISBN: 9788480883542

García-Ponce, Damián; Smolak-Lozano, Emilia (2013). “Comunicación de crisis: compilación y revisión de teorías y taxonomías prácticas desde una perspectiva cualitativa". Vivat academia, v. 124, pp. 51-67.

https://doi.org/10.15178/va.2013.124.51-67

Gil-Calvo, Enrique (2009). “Riesgo, incertidumbre y medios de comunicación”. En: Moreno-Castro, Carolina (ed.). Comunicar los riesgos. Ciencia y tecnología en la sociedad de la información. Madrid: Biblioteca Nueva, pp. 185-198. ISBN: 9788497429269

González-Herrero, Alfonso (1998). Marketing preventivo. La comunicación de crisis en la empresa. Barcelona: Bosch Comunicación. ISBN: 9788476765197

González-Herrero, Alfonso; Pratt, Cornelius B. (1996). “An integrated symmetrical model for crisis-communications management". Journal of public relations research, v. 8, n. 2, pp. 79-105.

https://doi.org/10.1207/s1532754xjprr0802_01

Gonzalo-Iglesia, Juan-Luis; Farré-Coma, Jordi (2011). Teoría de la comunicación de riesgo. Barcelona: UOC. ISBN: 978 8497884457

Greenberg, Josh; Elliott, Charlene (2009). "A cold cut crisis: Listeriosis, Maple Leaf Foods and the politics of apology". Canadian journal of communication, v. 34, n. 2, pp. 189-204.

https://doi.org/10.22230/cjc.2009v34n2a2204

Howell, Gwyneth V. J.; Miller, Rohan (2010). "Maple leaf foods: Crisis and containment case study". Public communication review, v. 1, n. 1, pp. 47-56.

https://doi.org/10.5130/pcr.v1i1.1297

King, Thea; Cole, Martin; Farber, Jeffrey M.; Eisenbrand, Gerhard; Zabaras, Dimitrios; Fox, Edward M.; Hill, Jeremy P. (2017). "Food safety for food security: Relationship between global megatrends and developments in food safety". Trends in food science and technology, v. 68, pp. 160-175.

https://doi.org/10.1016/j.tifs.2017.08.014

Krippendorff, Klaus (1990). Metodología de análisis de contenido, teoría y práctica. Barcelona: Paidós. ISBN: 8475096271

Lerbinger, Otto (2011) The crisis manager: Facing risk and responsibility. New York: Routledge. ISBN: 9780415892315

Liu, Brooker-Fisher; Faustino, Julia-Daisy (2014). “Beyond image repair: Suggestions for crisis communication theory development". Public relations review, v. 40, n. 3, pp. 543-546.

https://doi.org/10.1016/j.pubrev.2014.04.004

López-Villafranca, Paloma (2012). "Los encuadres sanitarios en prensa. Gripe A y bacteria E. Coli”. Revista internacional de relaciones públicas, v. 2, n. 4, pp. 221-246.

https://doi.org/10.5783/RIRP-4-2012-10-221-246

López-Villafranca, Paloma (2013). "Los encuadres de la prensa española sobre la crisis sanitaria por la bacteria E. Coli”. Disertaciones, v. 6, n. 2, pp. 112-144.

https://www.redalyc.org/pdf/5115/511555576007.pdf

Losada-Díaz, José-Carlos (2010). Comunicación en la gestión de crisis. Barcelona: Editorial UOC. ISBN: 9788497888813

Lukes, Steven (2007). El poder. Un enfoque radical. Madrid: Siglo XXI de España Editores. ISBN: 9788432312816

Mayoral-Sánchez, Javier (2005). “Fuentes de información y credibilidad periodística”. Estudios sobre el mensaje periodístico, v. 11, pp. 93-102.

https://revistas.ucm.es/index.php/ESMP/article/view/ESMP0505110093A

https://doi.org/10.5209/ESMP

Meisner, Colten; Hinderaker, Amorette (2020). "Reframed crisis narratives: Localized agenda setting, product loyalty, and pre-existing organizational narratives in the 2015 Blue Bell Creameries listeriosis crisis". Western journal of communication, v. 84, n. 2, pp. 186-203.

https://doi.org/10.1080/10570314.2019.1637015

Mitroff, Ian; Pearson, Christine (2002). Cómo gestionar una crisis. Madrid: Gestión 2000. ISBN: 9788480887823

Moreno-Millán, Emilio (2008). "Gestión de la comunicación y la información en emergencia, desastres y crisis sanitarias". Emergencias: Revista de la Sociedad Española de Medicina de Urgencias y Emergencias, v. 20, n. 2, pp. 117-124. http://emergencias.portalsemes.org/descargar/gestion-de-la-informacion-y-la-comunicacion-en-emergencias-desastresy-crisis-sanitarias 
Ogrizek, Michel; Guillery, Jean-Michel (1997). La communication de crise (Que sais-je?). Paris: Presses Universitaires de France. ISBN: 9782130485841

Opat, Kelsi; Magness, Haley; Irlbeck, Erica (2018). "Blue Bell's Facebook posts and responses during the 2015 listeria crisis: A case study". Journal of applied communications, v. 102, n. 4.

https://doi.org/10.4148/1051-0834.2232

Piñuel-Raigada, José-Luis (1997). Teoría de la comunicación y gestión de las organizaciones. Madrid: Síntesis. ISBN: 978 8477384908

Quesada, Juan (2016). “Estrategias de negociación en situaciones de crisis en la Administración Local”. Más poder local, n. 29, pp. 22-23.

https://dialnet.unirioja.es/servlet/articulo?codigo $=5680447$

Ren, Yifei (2018). Managing a food health crisis: Perceptions and reactions to different response strategies. Graduate theses and dissertations, University of South Florida.

https://scholarcommons.usf.edu/etd/7563

Revuelta, Gema; De-Semir, Vladimir; Armengou, Clara; Cots, Emma; Gonzalo, Carlos; Saladié, Núria; Sarukhan, Adelaida (2014). Informe Quiral 2014. La comunicación pública sobre la enfermedad del Ébola. Medicina, comunicación y sociedad. Fundació Vila Casas. Universidad Pompeu Fabra. Barcelona.

http://ccs.upf.edu/wp-content/uploads/InformeQuiral2014.pdf

Rocamora-Villena, Verónica (2012). “De la comunicación de riesgos a la comunicación de crisis: la OMS en el caso de la gripe A (H1N1)". En: III Congreso Internacional de la Asociación Española de Investigación de la Comunicación. https://bit.ly/32/tU8S

Rodríguez-Andrés, Roberto; Sádaba-Garraza, Teresa (1999). Periodistas ante conflictos: El papel de los medios de comunicación en situaciones de crisis. Pamplona: Eunsa. ISBN: 9788431317324

Rodríguez-González, María-del-Mar; Marauri-Castillo, Iñigo; Armentia-Vizuete, José-Ignacio; Marín-Murillo, Flora (2017). "Krisien komunikazioa: politika eta osasun agintaritzen kudeaketa arrautzaren krisian Euskadin (Comunicación de crisis: gestión de los responsables políticos y de salud en la crisis del huevo en Euskadi)". Mediatika: Cuadernos de medios de comunicación, n. 16, pp. 141-158.

http://www.eusko-ikaskuntza.eus/PDFAnlt/mediatika/16/Mediatika_16_141-158.pdf

Saura-Pérez, Pilar (2005). La gestión de la comunicación de crisis en el sector de la alimentación y bebidas en España. Madrid: Universidad Pontificia de Comillas. ISBN: 8484681629

Saura-Pérez, Pilar; García-García, Francisco (2010). “La comunicación de crisis como elemento clave de la comunicación empresarial". Icono 14, v. 2, pp. 42-56.

https://doi.org/10.7195/ri14.v8i2.245

Schwarz, Andreas (2016). "La investigación en la comunicación de crisis en la era de la globalización y la hibridación”. En: Mercado-Sáez, María-Teresa; Chávez, Manuel (eds.). La comunicación de situaciones en riesgo y crisis. Valencia, Tirant Humanidades, pp. 29-58. ISBN: 9788416349715

Segarra-Saavedra, Jesús; Martínez-Sala, Alba-María; Monserrat-Gauchi, Juan (2019). "Planificación estratégica de la comunicación integrada". Razón y palabra, v. 22, n. 3 102, pp. 152-178.

http://www.revistarazonypalabra.org/index.php/ryp/article/view/1263

Semetko, Holli A.; Valkenburg, Patti M. (2000). "Framing European politics: a content analysis of press and television news". Journal of communication, v. 50, n. 2, pp. 93-109.

https://doi.org/10.1111/j.1460-2466.2000.tb02843.x

Sotelo-Enríquez, Carlos (2001). Introducción a la comunicación institucional. Barcelona: Ariel. ISBN: 9788434412835

Tankard, James (2001). "The empirical approach to the study of media framing". In: Reese, Stephen D.; Gandy, Oscar H.; Grant, August E. (eds.). Framing public life: Perspectives on media and our understanding of the social world. Mahwah, N. J.: Lawrence Erlbaum, pp. 95-106. ISBN: 9780805849264

Unión Europea (2002). “Reglamento (CE) n 178/2002 del Parlamento Europeo y del Consejo de 28 de enero de 2002 por el que se establecen los principios y los requisitos generales de la legislación alimentaria, se crea la Autoridad Europea de Seguridad Alimentaria y se fijan procedimientos relativos a la seguridad alimentaria". Diario oficial, n. L 031, 1 febrero. https://eur-lex.europa.eu/legal-content/ES/TXT/?uri=celex:32002R0178

Unión Europea (2004). “Reglamento n. 852/2004 del Parlamento Europeo y del Consejo, de 29 de abril de 2004, relativo a la higiene de los productos alimenticios". Diario oficial, n. 139, 30 abril.

https://www.boe.es/buscar/doc.php?id=DOUE-L-2004-81035 
Van-der-Meer, Toni G. L. A.; Verhoeven, Joost W. M. (2014). "Emotional crisis communication”. Public relations review, v. 40, n. 3, pp. 526-536.

https://doi.org/10.1016/j.pubrev.2014.03.004

Vázquez-Gestal, Montse; Fernández-Souto, Ana-Belén (2014). “La gestión comunicativa de la actividad mediática entre España y Alemania en el contexto de la crisis de los pepinos”. Historia y comunicación social, v. 19, pp. 153-165. https://doi.org/10.5209/rev_HICS.2014.v19.44948

Véliz-Montero, Fernando (2006). "Cambio de mirada en las organizaciones. Comunicación en 360 grados". Chasqui. Revista latinoamericana de comunicación, n. 93. pp. 62-66.

https://revistachasqui.org/index.php/chasqui/article/view/225

Vreese, Claes H. (2005). "News framing: Theory and typology". Information design journal + document design, v. 13, n. 1, pp. 51-56.

https://doi.org/10.1075/idjdd.13.1.06vre

Westphalen, Marie-Helène; Piñuel-Raigada, José-Luis (1993). La dirección de comunicación. Madrid: Ediciones El Prado. ISBN: 9788478383832

Xifra, Jordi (2009). Comunicación proactiva: la gestión de conflictos potenciales en las organizaciones. Madrid: Gedisa. ISBN: 9788497843201

\section{Realiza tu proyecto}

Por una biblioteca pública social e inclusiva

En nuestra web te ofrecemos unas pautas

para facilitar la formulación de tu proyecto

fundacionbibliotecasocial.org

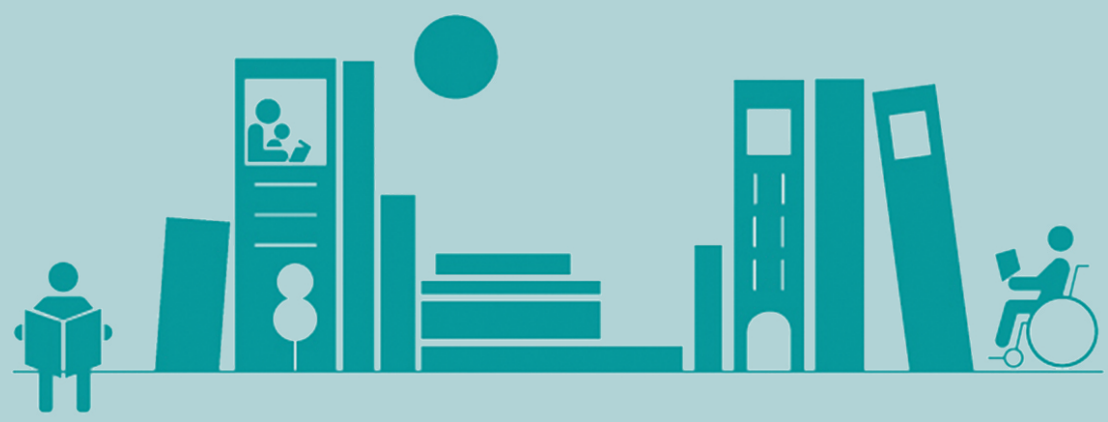

La Fundación Biblioteca Social es una institución sin ánimo de lucro cuyo objetivo es contribuir a compensar los desequilibrios sociales, apoyando proyectos que llevan a cabo las bibliotecas públicas dirigidos a los sectores más vulnerables de la sociedad.

La Fundación se mantiene con aportaciones privadas. No acepta ayudas ni subvenciones públicas. ¿Colaboras para dar mayor visibilidad al rol social de la biblioteca?

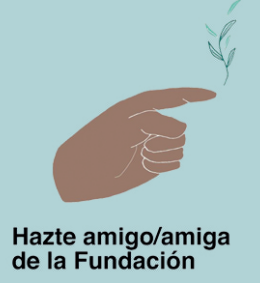

